\title{
Optimal placement of static VAR compensator in transmission network for loss minimization and voltage deviation index reduction
}

\author{
Mohammad Haikal Aziz ${ }^{1 *}$, Mohd Helmi Mansor ${ }^{1}$, Ismail Musirin' ${ }^{2}$, Shahrizal Jelani ${ }^{3}$ and Saiful \\ Amri Ismail ${ }^{2}$ \\ Department of Electrical and Electronics Engineering, College of Engineering, Universiti Tenaga Nasional \\ (UNITEN), Selangor, Malaysia ${ }^{1}$ \\ Faculty of Electrical Engineering, Universiti Teknologi MARA (UiTM), Selangor, Malaysia ${ }^{2}$ \\ Faculty of Engineering, Technology and Built Environment, UCSI University, Kuala Lumpur, Malaysia ${ }^{3}$
}

Received: 18-October-2020; Revised: 16-February-2021; Accepted: 17-February-2021

(C)2021 Mohammad Haikal Aziz et al. This is an open access article distributed under the Creative Commons Attribution (CC BY) License, which permits unrestricted use, distribution, and reproduction in any medium, provided the original work is properly cited.

\begin{abstract}
This paper presents the implementation of Artificial Immune System (AIS) for total system loss minimization and Voltage Deviation Index (VDI) reduction, along with the identification of the Static VAR Compensator (SVC) sizing. The objective of this optimization problem is to find the best location and sizing of SVC units that result in low total system loss and low value of VDI. Two case studies have been introduced in solving the problem: (N-1) line contingency and reactive power loading. It is found that the proposed approach is suitable to be used to solve optimal SVC placement problem as it has managed to achieve minimum total system loss and lower down the value of VDI by finding the best location and size of the SVC units in the transmission network. For example, for case 1 ((N-1) line contingency), AIS found bus 11 and bus 13 are the suitable locations to install SVC1 and SVC2 with the corresponding sizes of 55.25 MVAR (injecting) and 53.04 MVAR (injecting), respectively for total system loss minimization. The loss has reduced from 17.68 MW to 15.84 MW after the installation of the SVC units.
\end{abstract}

Keywords

FACTS devices, Static VAR compensator, Voltage deviation index, Artificial immune system.

\section{Introduction}

In recent years, it can be seen there are many Flexible AC Transmission System (FACTS) devices installed in transmission networks. This is due to the complexity connection of transmission network and high penetration of renewable energy into the system [1]. FACTS devices are power electronic based devices that normally used with the combination of power system devices to improve the controllability and stability of transmission network and to increase the capacity for power transfer. Under normal and contingency conditions, FACTS devices allow active power to flow through transmission lines. FACTS controllers have the ability to regulate the parameters governing the operation of the transmission network, including series impedance, shunt impedance, current, voltage, phase angle, and therefore oscillation damping at multiple frequencies below the rated frequency $[2,3]$.

*Author for correspondence 405
Typical FACTS devices are Static VAR Compensator (SVC), Static Compensator (STATCOM), TCPST, etc. SVC is the most popular FACTS device used in transmission system. That is because it is cheaper than other FACTS devices. SVC is suitable for regulating voltage, refining transient stability, reducing temporary overvoltage and increasing power damping. The main function of the $\mathrm{SVC}$ is to regulate the voltage at the selected bus by regulating the reactive injection location [4]. SVC's characteristics are capacitive and inductive, which can be used to increase or decrease the reactance in transmission system. As a result, the static voltage safety margin improves the voltage profile and power losses decrease [5]. SVC can also generate and absorb reactive power at the connection point, usually in the center of the high-voltage transmission line. SVC has the ability to maintain the voltage magnitude of the long transmission line, thereby increasing the capacity of the transmission line. SVC controls the terminal voltage by regulating the 
amount of reactive power injected into or absorbed from the buses. SVC generates reactive power when the terminal voltage is low and absorbs reactive power when the terminal voltage is high [6].

An optimization technique is required for the placement of SVC in the transmission network. In the last 15 years, scientists and engineers have proposed many optimization techniques to find optimal location to install SVC in transmission network. Some of the techniques are Cuckoo search algorithm [7], Branch \& Bound (B\&B) algorithm [8], mesh adaptive direct search algorithm [9], Particle Swarm Optimization (PSO) [10], etc. SVC optimal placement problems have been solved with several objectives such as to minimize system losses, to improve voltage stability, to increase worst-case power system reactive margin and to reduce installation cost.

This paper proposes to use a popular computational intelligence-based technique called the Artificial Immune System (AIS) to solve the optimal SVC placement problem. AIS has been used to solve several power system optimization problems like economic power dispatch, optimal distributed generation installation, load shading, estimation of network state, etc. AIS is used in conjunction with the VDI to optimally place the SVC in the transmission network. The goals of solving this optimization problem are to minimize power system losses and reduce VDI value. A reduced VDI value is crucial in ensuring transmission network voltage stability. The IEEE 30-Bus Reliability Test System (RTS) was used to demonstrate the implementation of AIS and VDI. Furthermore, two case studies were conducted to solve the SVC placement problem. First case is (N-1) line contingency, second case is reactive power loading. It is found that AIS and VDI find the best location and size of the SVC in transmission by giving low total system loss and low VDI.

\section{Methodology}

Based on the size of the IEEE 30-Bus RTS, it was decided to install two SVC units in the system. Figure 1 shows IEEE 30-Bus RTS. The system has six generators and forty-one transmission lines. The best location for SVC units is obtained from all system bus VDI values. VDI shows how the bus voltage has deviated from the benchmark value. The lower the VDI value, the better the bus. SVC units are installed at buses with two highest VDI values. The VDI can be written mathematically as follows:

$\Delta V_{\Sigma}=\sum_{i=1}^{b}\left(\frac{V_{r e f, i}-V_{i}}{V_{\text {ref }, i}}\right)^{2}$

Where $V_{\text {ref,i } i}$ is the benchmark voltage at $i^{\text {th }}$ bus and $V_{i}$ is voltage at $i^{\text {th }}$ bus.

Subsequently, the size of the SVC units is found using AIS. It is either supply reactive power or absorb reactive power to the system.

There are two case studies conducted for solving optimal SVC placement problem: (N-1) line contingency and reactive power loading. After knowing the best location of SVC units from the VDI values, AIS is launched to obtain the best sizing for the SVC units. Figure 2 illustrates AIS' process of finding optimal SVC units. The figure is explained in detail as follows:

Step 1: Initialization

During initialization process, random value of control variables is generated to form a population with the size of twenty. The control variable is the size of the two SVC units. The SVC units' maximum and minimum capacity are considered while generating the initial values.

Step 2: Cloning Process

The AIS algorithm continues with the cloning process. During this process, the initial population is multiplied by ten to produce a big population with the size of two hundred. At the end of the cloning process, the fitnesses of the optimization are calculated. The fitnesses for this problem are total system loss and VDI. Equation (1) is used to calculate the VDI and equation (2) is used to calculate the total system loss.

$P_{\text {loss }}=\sum_{k=1}^{l} g_{k}\left[V_{i}^{2}+V_{j}^{2}-2 V_{i} V_{j} \cos \left(\delta_{i}-\delta_{j}\right), k \in\right.$ $\{1,2, \ldots, l\}$

Where:

$g_{k} \quad=\quad$ conductance of kth line, $V_{i}$ and $\delta_{i}=\quad$ bus $i$ voltage magnitude and angle, respectively, $V_{j}$ and $\delta_{j}=\quad$ bus $j$ voltage magnitude and angle, respectively, and

$l \quad=\quad$ number of transmission network lines. 


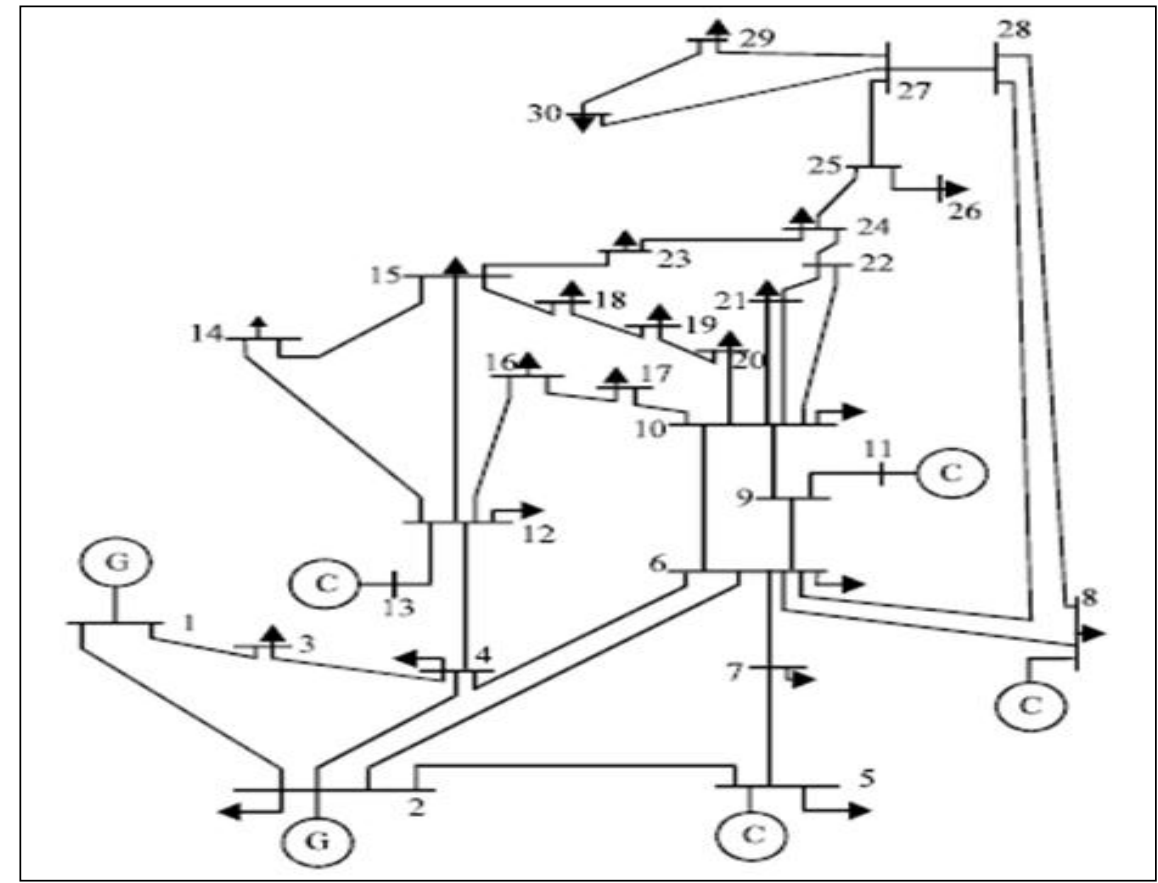

Figure 1 IEEE 30-Bus RTS [11]

Step 3: Mutation

Subsequently, the cloned population is mutated using Gaussian mutation method to produce a new population with the same size. The Gaussian mutation equation can be represented as follows:

$X_{i+m, j}=X_{i, j}+N\left(0, \beta\left(X_{j, \max }-X_{j, \min }\right)\left(\frac{f_{i}}{f_{\max }}\right)\right)$

Where:

$X_{i+m, j}=$ mutated individual,

$X_{i, j} \quad=$ cloned individual,

$N=$ random variable in Gaussian with mean $\mu$ and variance $\gamma^{2}$,

$\beta=$ mutation scale, $0<\beta<1$,

$X_{j, \text { max }}=$ maximum value of control variable,

$X_{j, \min }=$ minimum value of control variable,

$f_{i} \quad=$ fitness value for the $i^{\text {th }}$ random number, and

$f_{\max }=$ maximum fitness value

Step 4: Selection
In this selection process, twenty best individuals are selected for the next process. Firstly, the two hundred mutated individuals are ranked in ascending order with respect to their fitness value which is total system loss. The individual with lowest fitness value will be at the top of the matrix while the individual with highest fitness value will be at the bottom. After the population is ranked, twenty top individuals will be picked to undergo the convergence test.

\section{Step 5: Convergence Test}

Convergence test is used to indicate the AIS algorithm has found the global optima. This is done by setting a stopping criterion of the difference between the $1^{\text {st }}$ and the $20^{\text {th }}$ fitness value is 0.00001 . It is said to be converged if the difference is equal or less than 0.00001. It is as illustrated in equation (4).

Fitness value $_{20 t h}-$ Fitness value $_{1 s t} \leq 0.00001$ 


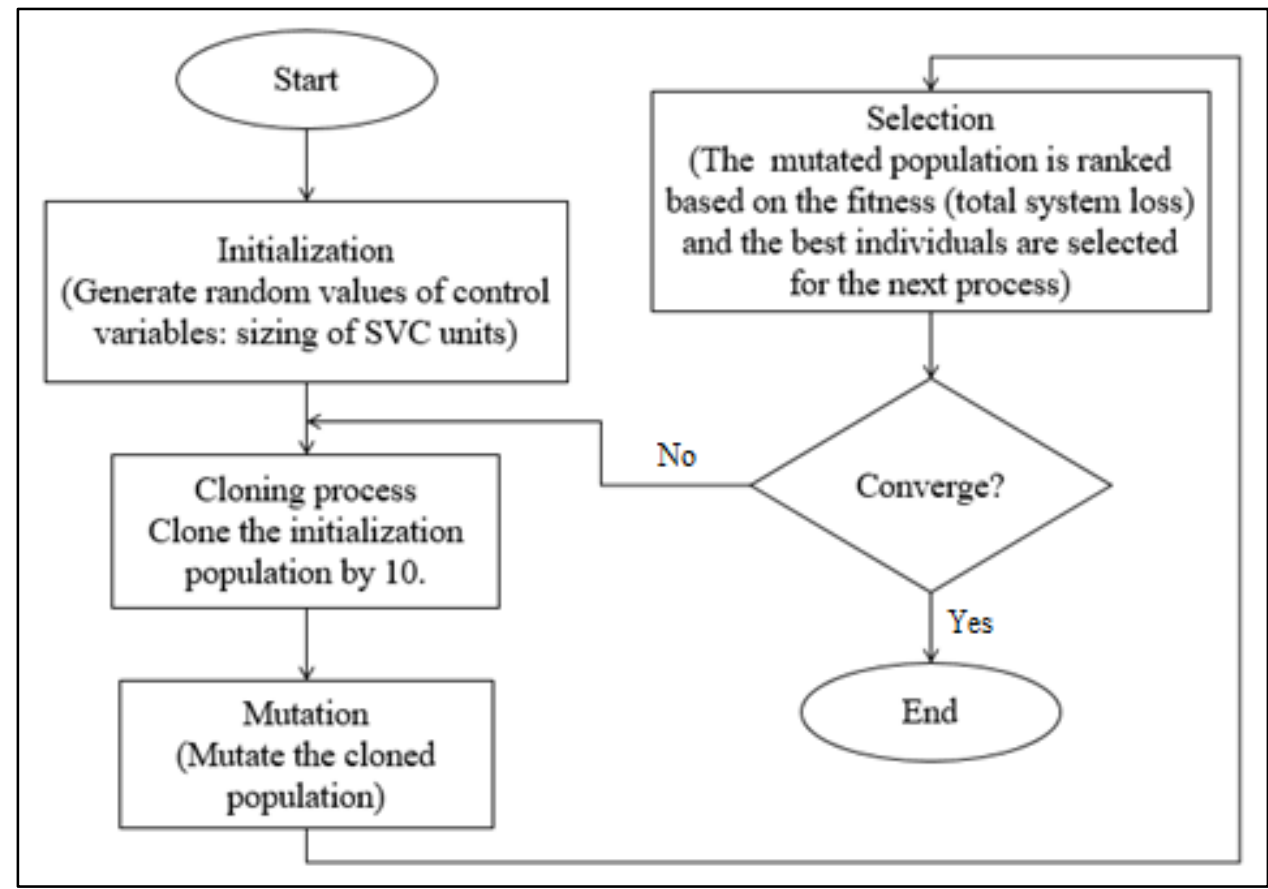

Figure 2 AIS algorithm for finding the optimal size of SVC

\section{Results and discussion}

There are two case studies conducted in finding optimal placement of SVC units in the IEEE 30-Bus RTS using VDI and AIS. It starts with (N-1) Line Contingency and followed by reactive power loading. For each case, the optimization problem is solved with two different objectives: total system loss minimization and VDI reduction.

\subsection{Case 1: (N-1) line contingency}

For the first case, one weak transmission line is put on outage. For the IEEE 30-Bus RTS, line 10-22 is the weak bus and it is put on outage. In this case, the buses with the highest values of VDI are buses 11 and 13. Therefore, SVC are installed at these buses. AIS is launched subsequently to identify the SVC units' best size. Table 1 shows the optimization result for this case.
It can be seen from Table 1 that AIS the sizes of SVC1 and SVC2 are 55.25 MVAR and 53.04 MVAR, respectively. Furthermore, both SVC units are absorbing reactive power from the system. At the same time, the total system loss has reduced from 17.68 MW to $15.84 \mathrm{MW}$ when SVC units are installed at bus 11 and bus 13 with the mentioned sizes.

Table 2 shows the optimization result for VDI reduction for the first case study. As referred to the table, it can be observed that the lowest VDI value in the IEEE 30-Bus RTS has reduced to 0.0066 from 0.0211 after SVC1 and SVC2 are optimally installed at bus 11 and bus 13 with the sizes of $67.56 \mathrm{MVAR}$ (absorbing) and 13.72 MVAR (absorbing), respectively. This shows that SVC units have helped to maintain the voltage stability of the transmission network when one transmission line is on outage.

Table 1 Optimization results from AIS implementation for case 1 (total system loss minimization)

\begin{tabular}{lccc}
\hline \multirow{2}{*}{ SVC Unit } & Location (Bus No.) & \multirow{2}{*}{ Size (MVAR) } & \multicolumn{2}{c}{ Total system loss (MW) } \\
$S V C 1$ & 11 & -55.25 & Without SVC \\
\hline$S V C 2$ & 13 & -53.04 & 17.68 \\
\hline
\end{tabular}


Table 2 Optimization result from AIS implementation for case 1 (VDI reduction)

\begin{tabular}{lcccc}
\hline \multirow{2}{*}{ SVC Unit } & Location (Bus No.) & \multirow{2}{*}{ Size (MVAR) } & \multicolumn{2}{c}{ Lowest VDI Value } \\
\cline { 3 - 4 }$S V C 1$ & 11 & -67.56 & Without SVC & With SVC \\
\hline$S V C 2$ & 13 & -13.72 & 0.0211 & 0.0066 \\
\hline
\end{tabular}

3.2Case 2: reactive power loading

In this second case, the reactive power load of bus 26 is increased to 5 MVAR and 10 MVAR from its original load of 2.3 MVAR. This is because bus 26 is considered as one of the weak buses in the IEEE 30Bus RTS based on the study made in [12]. Similar to the first case, it was found that bus 11 and bus 13 have the highest VDI values compared to the other buses. Therefore, SVC1 and SVC2 are placed at the bus 11 and bus 13, respectively. Then, AIS is launched to obtain the best sizes of the two SVC units.

Table 3 shows the optimization result of total system loss minimization for the case study 2 when $Q_{\text {Load (26) }}=5$ MVAR and $Q_{\text {Load(26) }}=10$ MVAR. It is found that the total system loss for both conditions has reduced significantly to $16.22 \mathrm{MW}$ and 17.89 $\mathrm{MW}$ for $Q_{\text {Load (26) }}=5 \mathrm{MVAR}$ and $Q_{\text {Load(26) }}=10$ MVAR, respectively. The optimal locations of SVC1 and $S V C 2$ for condition $Q_{\operatorname{Load}(26)}=5 \mathrm{MVAR}$ are bus 11 and bus 13 with the sizes of 55.25 MVAR (absorbing) and 25.29 MVAR (absorbing), respectively. While for condition $Q_{\text {Load (26) }}=10$
MVAR, the best location are bus 11 and bus 13 with the sizes of 53.04 MVAR (absorbing) and 29.37 MVAR (absorbing), respectively.

Optimization result from AIS implementation for case study 2 of VDI reduction is tabulated in Table 4 . Based on the VDI values for all buses in the IEEE 30-Bus RTS, it is found that the best location for SVC1 and SVC2 are bus 11 and bus 13 for both conditions of $Q_{\text {Load(26). }}$.

AIS managed to lower down the value of the lowest VDI in the system from 0.0206 to 0.0072 for $Q_{\text {Load(26) }}$ $=5 \mathrm{MVAR}$ and from 0.0199 to 0.0026 for $Q_{\operatorname{Load}(26)}=$ 10 MVAR after the SVC units are installed. This indicates that the transmission network's voltage stability has improved after the VDI is optimized using AIS for the both conditions of $Q_{\text {Load (26) }}$. The sizes of $S V C 1$ and $S V C 2$ for $Q_{\operatorname{Load}(26)}=5 \mathrm{MVAR}$ are 13.72 MVAR (absorbing) and 82.13 MVAR (supplying), respectively. While for $Q_{\text {Load(26) }}=10$ MVAR, the sizes are 82.66 MVAR (absorbing) and 59.24 MVAR (absorbing) for SVCl and SVC2, respectively.

Table 3 Optimization result from AIS implementation for case 2 (total system loss minimization)

\begin{tabular}{|c|c|c|c|c|}
\hline \multicolumn{5}{|c|}{$Q_{\text {Load (26) }}=5$ MVAR } \\
\hline \multirow{2}{*}{ SVC Unit } & \multirow{2}{*}{ Location (Bus No.) } & \multirow{2}{*}{ Size (MVAR) } & \multicolumn{2}{|c|}{ Total System Loss (MW) } \\
\hline & & & Without SVC & With SVC \\
\hline SVC1 & 11 & -55.25 & \multirow{2}{*}{17.72} & \multirow{2}{*}{16.22} \\
\hline$S V C 2$ & 13 & -25.29 & & \\
\hline \multicolumn{5}{|c|}{$Q_{\text {Load(26) }}=10 \mathrm{MVAR}$} \\
\hline \multirow{2}{*}{ SVC Unit } & \multirow{2}{*}{ Location (Bus No.) } & \multirow{2}{*}{ Size (MVAR) } & \multicolumn{2}{|c|}{ Total System Loss (MW) } \\
\hline & & & Without SVC & With SVC \\
\hline$S V C 1$ & 11 & -53.04 & \multirow{2}{*}{18.23} & \multirow{2}{*}{17.89} \\
\hline$S V C 2$ & 13 & -29.37 & & \\
\hline
\end{tabular}

Table 4 Optimization result from AIS implementation for case 2 (VDI reduction)

\begin{tabular}{|c|c|c|c|c|}
\hline \multicolumn{5}{|c|}{$Q_{\text {Load(26) }}=5$ MVAR } \\
\hline \multirow{2}{*}{ SVC Unit } & \multirow{2}{*}{ Location (Bus No.) } & \multirow{2}{*}{ Size (MVAR) } & \multicolumn{2}{|c|}{ Lowest VDI Value } \\
\hline & & & Without SVC & Without SVC \\
\hline SVC1 & 11 & -13.72 & \multirow{2}{*}{0.0206} & \multirow{2}{*}{0.0072} \\
\hline$S V C 2$ & 13 & 82.13 & & \\
\hline \multicolumn{5}{|c|}{$Q_{\text {Load (26) }}=10 \mathrm{MVAR}$} \\
\hline \multirow{2}{*}{ SVC Unit } & \multirow{2}{*}{ Location (Bus No.) } & \multirow{2}{*}{ Size (MVAR) } & \multicolumn{2}{|c|}{ Lowest VDI Value } \\
\hline & & & Without SVC & With SVC \\
\hline SVC1 & 11 & 82.66 & \multirow{2}{*}{0.0199} & \multirow{2}{*}{0.0026} \\
\hline$S V C 2$ & 13 & 59.24 & & \\
\hline
\end{tabular}




\section{Conclusion}

The implementation of Artificial Immune System (AIS) for total system loss minimization and Voltage Stability Index (VDI) reduction has been presented in this paper, along with the identification of the SVC sizings. Two case studies have been conducted, which are (N-1) line contingency and reactive power loading to investigate the capability of the proposed approach in optimizing two different objective functions: total system loss and VDI reduction. The proposed approach successfully minimized the total system loss and the lowest value of VDI for the IEEE 30-Bus RTS by placing the two SVC units at optimal locations with optimal sizing. For future work, instead of using VDI to find the optimal location and AIS for the optimal sizing, both location and sizing of SVC can be found using the computational intelligence technique of AIS. This requires a modification on the current algorithm. Furthermore, other recent optimization techniques such as Symbiotic Organism Search (SOS) and Firefly Algorithm (FA) can be used to solve this optimal SVC placement problem more efficiently.

\section{Acknowledgment}

The authors would like to acknowledge the Universiti Tenaga Nasional (UNITEN) for the financial support of this project. This research is supported by UNITEN under the BOLD Research Grant 2020 with project code: UNITEN/RMC(BOLD)/1/14/AL/2020/59.

\section{Conflicts of interest}

The authors have no conflicts of interest to declare.

\section{References}

[1] Zamani MK, Musirin I, Suliman SI, Mustaffa SA, Ali NZ, Mansor MH, Hamid ZA. Optimal TCSC allocation via chaotic immune symbiotic organisms search for voltage profile improvement. In E3S web of conferences 2020 (p. 03002). EDP Sciences.

[2] Kumar BS, Suryakalavathi M, Kumar GN. Optimal power flow with static VAr compensator using galaxy based search algorithm to minimize real power losses. Procedia Computer Science. 2016; 92:42-7.

[3] Malatji EM, Twala B, Mbuli N. Optimal placement model of multi-type FACTS devices in power system networks on a limited budget. In AFRICON 2017 (pp. 1296-300). IEEE.
[4] Bhattacharyya B, Goswami SK. Optimal planning for the placement of facts devices by differential evolution technique for the increased loadabilty of a power system. In Asia-pacific power and energy engineering conference 2012 (pp. 1-4). IEEE.

[5] Razali NS, Roslan N, Mansor MH, Musirin I, Shaaya SA, Jelani S. Optimal reactive power control using compensating capacitor based on artificial immune system. International Journal of Advanced Trends in Computer Science and Engineering. 2019; 8(1.3):3816.

[6] Gitizadeh M, Kalantar M. A new approach for congestion management via optimal location of FACTS devices in deregulated power systems. In 2008 third international conference on electric utility deregulation and restructuring and power technologies 2008 (pp. 1592-7). IEEE.

[7] Ghorbani A, Khederzadeh M, Mozafari B. Impact of SVC on the protection of transmission lines. International Journal of Electrical Power \& Energy Systems. 2012; 42(1):702-9.

[8] Nguyen KP, Fujita G, Dieu VN. Cuckoo search algorithm for optimal placement and sizing of static var compensator in large-scale power systems. Journal of Artificial Intelligence and Soft Computing Research. 2016; 6(2):59-68.

[9] Silva MC, Belati EA. Allocation of static VAr compensators using optimal reactive power flow and branch \& bound algorithm. IEEE Latin America Transactions. 2016; 14(5):2194-200.

[10] Qi J, Huang W, Sun K, Kang W. Optimal placement of dynamic var sources by using empirical controllability covariance. IEEE Transactions on Power Systems. 2016; 32(1):240-9.

[11] Huang JS, Jiang ZH, Negnevitsky M. Loadability of power systems and optimal SVC placement. International Journal of Electrical Power \& Energy Systems. 2013; 45(1):167-74.

[12] Aziz T, Saha TK, Mithulananthan N. Identification of the weakest bus in a distribution system with load uncertainties using reactive power margin. In Australasian universities power engineering conference 2010 (pp. 1-6). IEEE.

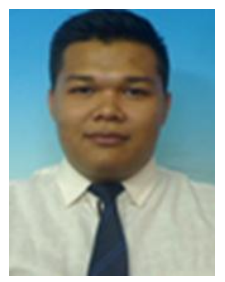

Mohammad Haikal Aziz is currently studying Bachelor's in Electrical Power Engineering at Universiti Tenaga Nasional, Malaysia.

Email: haikal.aziz96@gmail.com 


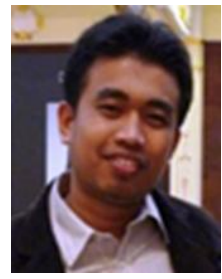

Dr. Mohd Helmi Bin Mansor was born in Muar, Johor, Malaysia in 1983. He received his Diploma in Electrical Engineering (Power) and Bachelor of Electrical Engineering (Hons) from Universiti Teknologi MARA (UiTM), Malaysia in 2004 and 2008, respectively. $\mathrm{He}$ possesses $\mathrm{MSc}$ in Sustainable Electrical Power from Brunel University, United Kingdom. He received his $\mathrm{PhD}$ from Universiti Teknologi MARA (UiTM), Malaysia in 2020. He joined Malaysian electricity company, Tenaga Nasional Berhad (TNB) in 2008 as an electrical engineer. Currently, he is a senior lecturer at College of Engineering, Universiti Tenaga Nasional, Malaysia. His research interest includes application of Computational Intelligence in Power System Optimization, Power System Studies and Renewable Energy. He is registered as a graduate engineer with the Board of Engineers Malaysia (BEM) and graduate member with the Institution of Engineers, Malaysia (IEM). He is also a member of the Institution of Engineering and Technology (IET).

Email: mhelmi@uniten.edu.my

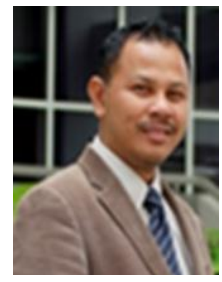

Prof. Ir. Dr. Ismail Bin Musirin obtained Bachelor of Electrical Engineering (Hons) in 1990 from Universiti Teknologi Malaysia, MSc Pulsed Power Technology in 1992 from University of Strathclyde, United Kingdom and $\mathrm{PhD}$ in Electrical Engineering from Universiti Teknologi MARA (UiTM), Malaysia in 2005. He is currently a Professor of Power System at the Faculty of Electrical Engineering, UiTM and headed the Power System Operation (POSC) Computational Intelligence Research Group. He has authored 2 books published, over 350 papers in international indexed journals and conferences. He is also an international journal reviewer for IEEE Transactions, Elsevier Science, WSEAS, John Wiley, IET and some other publishers. He has chaired more than 20 international conference since 2007. To date, he has delivered keynote speeches at Cambridge University, United Kingdom, Dubai, Korea and Malaysia. He has also been given opportunity to evaluate research grants at the national and international levels. His research interest includes Artificial Intelligence, Optimization Techniques, Power System Analysis, Renewable Energy, Distributed Generation and Power System Stability. $\mathrm{He}$ is a professional engineer and a senior member of International Association of Computer Science and Information Technology (IACSIT), member of Artificial Immune System Society (ARTIST) and member of International Association of Engineers (IAENG), Hong Kong

Email: ismailbm1@gmail.com

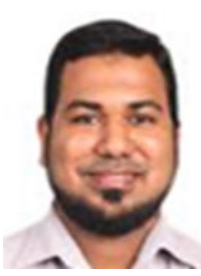

Shahrizal Jelani possess MSc in Electrical Engineering from Universiti Malaya, Malaysia. $\mathrm{He}$ is currently doing $\mathrm{PhD}$ in Electrical Engineering at Universiti Teknologi MARA, Malaysia. $\mathrm{He}$ is a tutor at UCSI University, Kuala Lumpur, Malaysia. His research interest includes Power System Studies and Artificial Intelligence.

Email: shahrizal@ucsiuniversity.edu.my

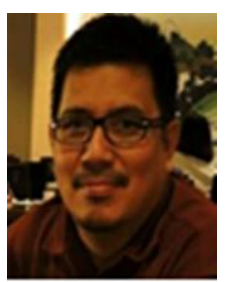

Saiful Amri Ismail possess MSc in Electrical Engineering from Universiti Malaya, Malaysia. $\mathrm{He}$ is currently doing $\mathrm{PhD}$ in Electrical Engineering at Universiti Teknologi MARA, Malaysia. $\mathrm{He}$ is an electrical engineer at Universiti Teknologi MARA and registered as a professional engineer under Borad of Engineers, Malaysia.

Email: saifu1370@uitm.edu.my 